\title{
UNESCO World Heritage properties in changing and dynamic environments: change detection methods using optical and radar satellite data
}

Athos Agapiou ${ }^{1,2^{*}}$ (1)

\begin{abstract}
The article presents recent capabilities of active and passive earth observation sensors along with related processing image chains, for monitoring UNESCO World Heritage properties. Exceptional heritage sites and landscapes are found in dynamic environments, whereas both anthropogenic and natural changes are observed. The use of radar and optical satellite imageries can be used as a systematic observation tool for stakeholders, to map drastic or slowly driven landscape changes towards the better protection and management of these sites and their surrounding areas. The study presents the results from the analysis of the European Copernicus Sentinel-1 and Sentinel-2 satellite images over two broader areas in the Eastern Mediterranean basin that hold important UNESCO World Heritage properties. Initially, a recent strong earthquake of a 6.7 magnitude scale in the Aegean Sea is studied using radar Sentinel-1 images. These radar images were processed through the Hybrid Pluggable Processing Pipeline (HyP3) cloud platform for analyzing both significant changes of the $\mathrm{W}$ (vertical transmit, vertical receive) and VH (vertical transmit, horizontal receive) backscattering signal as well as through an Interferometric Synthetic Aperture Radar (InSAR) analysis. Then, long-term changes in Cyprus during the last two decades are monitored by a Sentinel- 2 image compared to the European Corine Land Use Land Cover data of 2000. These changes are mapped after a supervised classification process using the random forest (RF) classifier. The overall results demonstrate that the recent developments of the space sector in all its segments (resolution of the sensors, the capacity to storage in the cloud, processing advancements and open-access datasets and tools) can be beneficial for monitoring UNESCO World Heritage properties.
\end{abstract}

Keywords: UNESCO World Heritage, Sentinel-1, Sentinel-2, InSAR, Change detection, Monitoring, Classification, Urbanization

\section{Introduction}

Based on the records, more than 1100 heritage sites are enlisted under the UNESCO World Heritage list, combining 869 cultural and 213 natural sites. In comparison, another 39 sites are characterized as mixed (both cultural

\footnotetext{
*Correspondence: athos.agapiou@cut.ac.cy

${ }^{1}$ Department of Civil Engineering and Geomatics, Faculty of Engineering and Technology, Cyprus University of Technology, Saripolou 2-8, 3036 Limassol, Cyprus

Full list of author information is available at the end of the article
}

and natural) [1]. UNESCO World Heritage properties are scattered in more than 160 state parties worldwide [2], in different landscapes that are continuously evolving and changing through time. Therefore, monitoring of these sites needs to be systematic and reliable at the same time. In addition, for the implementation of the Disaster Risk Management (DRM) cycle concept, as this was established after the International Strategy for Disaster Reduction [3], the "context" of a site cannot be considered as "constant". The "context" is dynamic, whereas various agents of deterioration and loss are taken place $[4,5]$.
Springer Open

(c) The Author(s) 2021. This article is licensed under a Creative Commons Attribution 4.0 International License, which permits use, sharing adaptation, distribution and reproduction in any medium or format, as long as you give appropriate credit to the original author(s) and the source, provide a link to the Creative Commons licence, and indicate if changes were made. The images or other third party material in this article are included in the article's Creative Commons licence, unless indicated otherwise in a credit line to the material. If material is not included in the article's Creative Commons licence and your intended use is not permitted by statutory regulation or exceeds the permitted use, you will need to obtain permission directly from the copyright holder. To view a copy of this licence, visit http://creativeco mmons.org/licenses/by/4.0/. The Creative Commons Public Domain Dedication waiver (http://creativecommons.org/publicdomain/ zero/1.0/) applies to the data made available in this article, unless otherwise stated in a credit line to the data. 
Environmental and landscape changes can occasionally be drastic with a catastrophic impact on the monument itself, as is the case of an earthquake event $[6,7]$. Other environmental agents linked with the economic and demographic growth and the land-use changes driven by the urbanization process may need more time to become detectable [8, 9]. Therefore, the systematic monitoring of heritage sites and their surrounding environment is important for their better understanding of the "context" in which a heritage site is situated [10].

Relevant studies [11-14] have already demonstrated the benefit of using archival information (historical maps and aerial images) to monitor and detect changes in the landscape. In addition, the role of earth observation for supporting cultural heritage management has been widely investigated in the recent past [15-18]. Due to their capacity to map in a short time extensive region, earth observation sensors have attracted the interest of scholars as this is evidence from the relevant literature landscape. In their recent work of Luo et al. [19] and Agapiou and Lysandrou [20], the relevant state-of-art regarding the use of remote sensing technology is presented. These reviews also included space-based observations for supporting archaeological research and heritage management. Indeed, in the recent past, and with the continuous improvements of the space sector technology, several applications and research studies have showcased the beneficial use of earth observation for monitoring archaeological landscapes. Lately, an unknown flooding event in the area of Sergiopolis in Syria was documented by high-resolution radar satellite images [21]. At the same time, the use of optical and radar sensors have been explored for the documentation of looted areas in the conflicted zone of Syria [22-24].

The latest potentials of space-based observation can be further maximized by using big-earth data analysis platforms, like the use of Google Earth Engine [25-27] and the NASA HyP3 cloud-based beta platform [28]. This new technological shift, observed in the space sectorboth in terms of availability of satellite sensors [29] and in terms of image processing- is expected to impact the traditionally known methods of remote sensing, and this will eventually -early or late-impact the remote sensing in archaeology.

This article aims to showcase some of the current potentials of the space sector for archaeological monitoring sites around the world, like those enlisted as UNESCO World Heritage monuments, through change detection techniques. The recent improvements of the satellite sensors and the exploitation of big-data cloud platforms may transform the existing way of monitoring heritage sites towards their systematic observation in the near future.
This paper showcases two examples from optical and radar satellite datasets for monitoring UNESCO World Heritage properties in the Eastern Mediterranean basin. The analysis is based on radar-image analysis through the HyP3 big data cloud platform and processing of optical satellite image through the use of open access platform. The overall results are presented below.

\section{Case study and methodology Case studies}

For the needs of the study, three UNESCO World Heritage sites, located in the area of the Eastern Mediterranean basin, were selected (Fig. 1). On the western part of the island of Cyprus, the "Paphos" World Heritage site was selected due to the dramatic urban expansion observed in the last decades in the area. The "Ephesus" (Turkey) and the "Pythagoreion and Heraion of Samos" (Greece) were also selected due to a recent strong earthquake of a 6.7 magnitude scale earthquake, just north of the island of Samos (see red star at Fig. 1). The "Paphos" site is situated in the District of Paphos in western Cyprus. The enlisted monument includes the remains of ancient "Nea Paphos" and the so-called "Tombs of the Kings". Below some further details regarding the selected case studies are provided.

The "Paphos" site, is situated in the District of Paphos in western Cyprus. The enlisted monument includes the remains of ancient "Nea Paphos" and the so-called "Tombs of the Kings". Archaeological excavations are still on-going in these areas in an attempt to better understand their role and function in the antiquity [30].

"Ephesus" comprises successive Hellenistic and Roman settlements. The Ancient City of Ephesus is an outstanding example of a Roman port city with a sea channel and harbour basin. Excavations at the area have revealed important findings of the Roman Imperial period, including the Library of Celsus and the Great Theatre, and a few remains of the famous Temple of Artemis, one of the "Seven Wonders of the World" [31].

The" Pythagoreion and Heraion of Samos" site was an important centre from the prehistoric era until almost the Middle Ages. The site is located on the northeast coast of the island of Samos, and it consists of the fortified city, known as Pythagoreion, and the ancient Temple of Hera (Heraion). The great Temple of Hera (Heraion) had its origins in the 8th century $\mathrm{BC}$ when it was the first Greek temple to be one hundred feet in length (Hecatompedos). A prominent feature of the site is the Eupalinus' tunnel dating from the 6th century $\mathrm{BC}$. The tunnel runs more than $1 \mathrm{~km}$ through the mountainside to bring water to the ancient city $\mathrm{BC}$ [32]. 


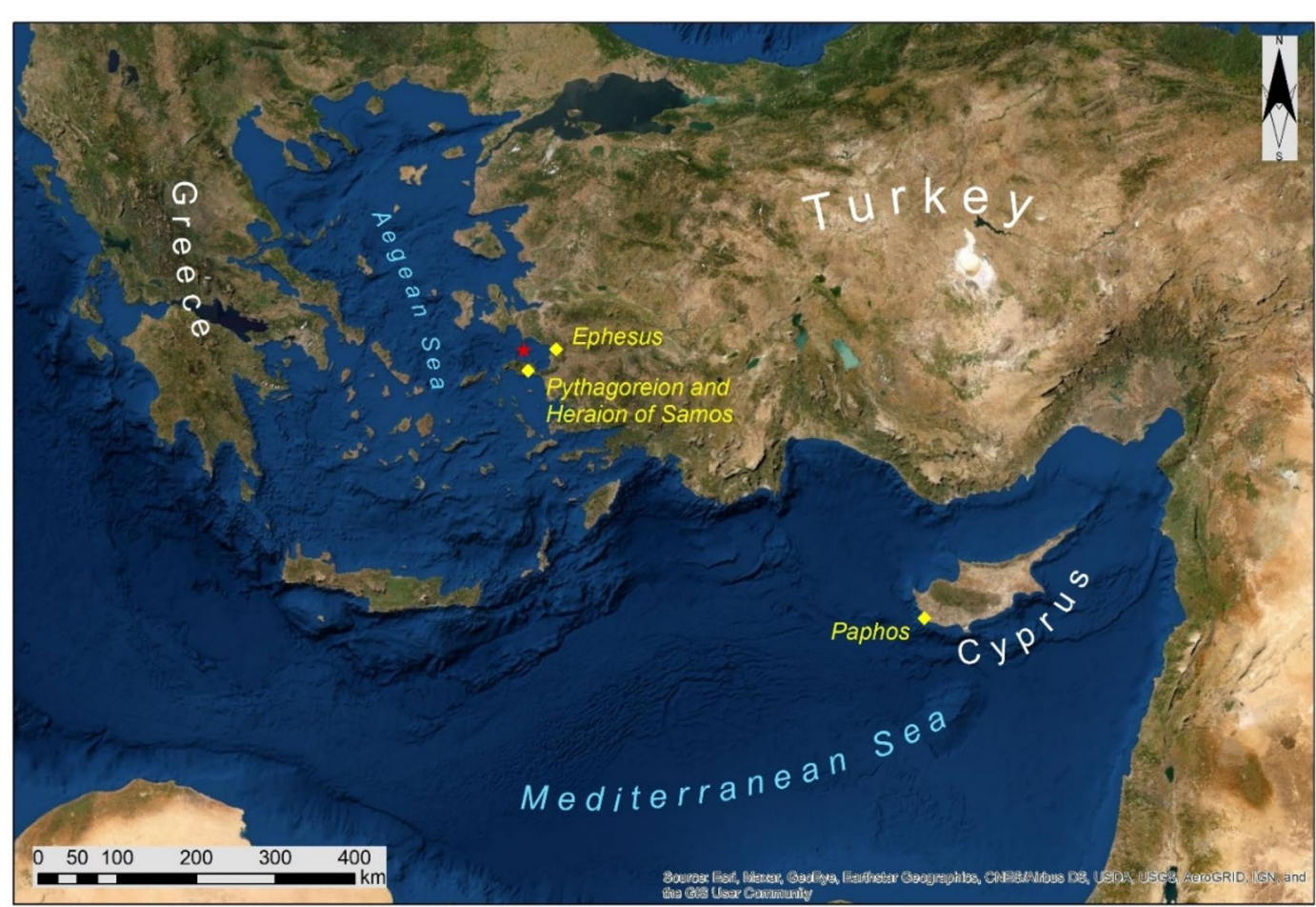

Fig. 1 Selected UNESCO World Heritage properties in the area of the eastern Mediterranean basin. The red star indicates the epicentre of a recent 6.7 magnitude scale earthquake

\section{Methodology \\ Radar processing}

The study exploits freely distributed and open-access satellite datasets provided by the European Copernicus programme [33]. Both radar and optical satellite images acquired from the Sentinel-1 and Sentinel-2 sensors can provide systematic datasets with almost global coverage. The radar Sentinel-A and $1 \mathrm{~B}$ sensors offer a sixday repeat cycle, with a repeat frequency (ascending/ descending) of 3 days at the equator and 1-3 days over Europe. These data are delivered to Copernicus services within an hour of acquisition [34]. Optical Sentinel-2A and $2 \mathrm{~B}$ sensors are set into a sun-synchronous orbit, providing data with a swath width of $290 \mathrm{~km}$ and a revisit time of 5 days at the equator and 2-3 days at mid-latitudes [35]. The radar Sentinel-1 datasets were obtained through the Alaska Satellite Facility (ASF) services [36], while the optical Sentinel-2 image was downloaded from the Copernicus Open Access Hub [37].

The radar images were explored to map changes that occurred after the strong earthquake, North of the island of Samos, and near to the UNESCO World Heritage areas of "Ephesus" (Turkey) and the "Pythagoreion and Heraion of Samos" (Greece). Radar Sentinel-1 images were processed through a big-data cloud platform, currently running in a beta version, operated by the NASA ASF services, the so-called Hybrid Pluggable Processing Pipeline (HyP3) [38]. HyP3 platform was initially used to estimate a change detection map using a pair of Radiometrically TerrainCorrect (RTC) Sentinel-1 data. The change detection map was estimated using the log difference for both $\mathrm{VV}$ and $\mathrm{VH}$ backscattering gamma 0 amplitude polarization of the RTC Sentinel-1 images, as well as using the coherence values. The $\log$ difference of the $\mathrm{VV}$ and the $\mathrm{VH}$ backscattering polarization was estimated using Eq. (1), while the degree of coherence was calculated upon Eq. (2), as shown below. The degree of coherence is defined as the normalized complex correlation coefficient of the complex backscatter intensities s1 and s2 [39].

$$
\text { Change detection }=\log 10(\mathrm{D} 2 / \mathrm{D} 1) \text {, }
$$

Where, D1 refers to the Sentinel-1 with an acquisition date (before the earthquake), and D2 refers to the Sentinel-1 image taken after the earthquake.

Coherence is estimated as the normalized complex correlation coefficient of the complex backscatter intensities $S_{1}$ and $S_{2}[39]$ and can be estimated using Eq. (2), where the * denotes the complex conjugate.

$$
\gamma=\left|\left\langle\mathrm{S}_{2} \mathrm{x} \mathrm{S}_{1} *\right\rangle / \sqrt{ }\left(\left\langle\mathrm{S}_{1} \times \mathrm{S}_{1} *\right\rangle\left\langle\mathrm{S}_{2} \times \mathrm{S}_{2} *\right\rangle\right)\right|
$$


Coherence values may range from 0 to 1 . Pixels with coherence values close to 1 indicate areas with a high coherence between the pairs of images. In contrast, values close to 0 indicate areas that have changed between the pairs of the overpasses of the Sentinel-1 radar sensors.

Both techniques are applied under the assumption that any changes can be linked to this natural event in between the overpass of the two images (before and after the earthquake). A significant change of the gamma-0 amplitude and coherence values can therefore be used as a first signal to local authorities to monitor the cultural heritage sites, including the UNESCO World Heritage properties. Positive values of the backscattering polarization indicate an increase in radar backscatter from the first date to the second, while negative values indicate a decrease.

Following the change detection analysis, the InSAR analysis map was performed. The InSAR analysis of an ascending and a descending pair of Sentinel-1 images was carried out using the Gamma software from the HyP3 platform. The InSAR methodology follows the following steps (further details can be found in [38]): step-1: define the overlapping area of the Sentinel-1 images. Step-2: download the Digital Elevation Model (DEM) and fused it with a weighted averaging approach over the area of interest. Step-3: create a lookup table for SLC co-registration between the DEM and Sentinel-1 datasets. Then the data are filtered with adaptive data filtering (ADF). Step-4: create a differential interferogram using the DEM height along with the co-registration with the DEM. Step5: removal of the flat earth phase. Step-6: remove the topographic phase. Step-7: refinement of the first image (before the event) with the master image (after the event). A check for convergence is performed using the azimuth offset as a limit (less than 0.02 pixels). Step-8: resampling of the slave to match the master image. Step-9: create the final interferogram. Step10: unwrapping the phase using the Minimum Cost Flow algorithm. The algorithm executes a global automatic optimization robust phase unwrapping taking into consideration disconnected areas of high coherence. Step-11: geocoding the results. The sub-products and the end-products developed through this processing chain of the InSAR analysis are also available for downloading by the end-user. The relative vertical displacement map was estimated using Eq. (3).

$$
\begin{aligned}
& \text { Vertical displacement } \\
& \quad=\left(\varphi_{\text {unwrapped }} \cdot \lambda(\mathrm{mm})\right) / 4 \pi \cdot \cos \theta_{\text {incident }}
\end{aligned}
$$

\section{Optical processing}

The optical Sentinel-2 image was used to map the land use properties over the archaeological site of "Paphos" in Cyprus. These results were then compared with the Corine Land Use Land Cover urban areas over the area as mapped in 2000. This comparison will illustrate the landuse changes, especially the urban sprawl's footprint for the last two decades over the area (i.e. 2000-2020).

The multispectral Sentinel-2 image was processed using the Random Forest (RF) classification algorithm [40]. The classification analysis was performed at the Sentinel Application Platform (SNAP) software [41], an open-source software, freely distributed to the scientific community.

\section{Datasets}

This section provides more details regarding the datasets used for the analysis presented in the following section. Regarding the change detection analysis using Eq. (1), a pair of Sentinel-1 images were used, as shown in Table 1. Two Sentinel-1B Interferometric Wide (IW) images with an acquisition date of 24th Oct. 2020 and 30th Oct. 2020 were analyzed for the change detection process. The

\begin{tabular}{|c|c|c|}
\hline Name & $\begin{array}{l}\text { Characteristics } \\
\text { Prior to the event (reference-D1) }\end{array}$ & $\begin{array}{l}\text { Characteristics } \\
\text { After the event (secondary-D2) }\end{array}$ \\
\hline Date & 24th Oct. 2020 & 30th Oct. 2020 \\
\hline Time (UTC) & $16: 06: 25$ & 16:07:09 \\
\hline Mode & Interferometric Wide swath (IW) & Interferometric Wide swath (IW) \\
\hline Satellite & Sentinel-1B & Sentinel-1B \\
\hline Absolute orbit number & 23957 & 22790 \\
\hline Pass direction & ASCENDING & ASCENDING \\
\hline Polarization & $\mathrm{V}+\mathrm{VH}$ & $\mathrm{V}+\mathrm{VH}$ \\
\hline Product type & Ground range (GRD) & Ground range (GRD) \\
\hline Path & 131 & 131 \\
\hline Frame & 119 & 119 \\
\hline
\end{tabular}

Table 1 Sentinel-1 images used for the change detection analysis 
images were taken from the same sensor (Sentinel-1B) and the same pass direction (ascending orbit) to minimize any noise.

For the InSAR and the coherence analysis, another two pairs of Sentinel-1B images in descending and ascending orbits were used. For the first pair, the images were taken on 30th Oct. 2020 and 05th Nov. 2020 in a descending orbit (Table 2), while for the second pair, the radar images were taken on 24th Oct. 2020 and 30th Oct. 2020 in ascending orbit (Table 3).

In addition, a Sentinel- 2 optical image was acquired over the Paphos district of Cyprus for mapping the urban fabric around the UNESCO World Heritage properties. The Sentinel-2 image was obtained from the Copernicus Sentinel Hub, accessed directly from the SNAP platform. The image was acquired in Level 2A, which is already geometric, radiometric, and atmospherically corrected, while the date of acquisition was 05th Oct. 2020. The classification results of this image were compared with the Corine Land Cover (CLC) 2000. The CLC is a European programme coordinated by the European Environment Agency (EEA), providing consistent and thematically detailed information on land cover and land cover changes across Europe. CLC products are based on the classification of satellite images by the national teams of the participating countrie-the EEA member and cooperating countries (EEA39). National CLC inventories are further integrated into a seamless land cover map of Europe. Further details can be found in [42].

\section{Results}

This section presents the overall results for all selected case studies after processing both radar and optical satellite data.

\section{Radar processing Change detection}

Figure 2 presents the results from the change detection analysis using the log difference of the $\mathrm{VV}$ and the $\mathrm{VH}$ backscattering polarization (see Eq. 1) and the Sentinel-1 dataset of Table 1. Significant backscattering polarization changes are highlighted with red and blue colour, indicating negative and positive differences. Even though this type of analysis needs to be further investigated for

Table 2 Sentinel-1 images used for the InSAR analysis (descending orbit)

\begin{tabular}{lll}
\hline Name & $\begin{array}{l}\text { Characteristics } \\
\text { Prior to the event (reference-D1) }\end{array}$ & $\begin{array}{c}\text { Characteristics } \\
\text { After the event (secondary-D2) }\end{array}$ \\
\hline Date & 30 th Oct. 2020 & 05th Nov. 2020 \\
Time (UTC) & $04: 14: 39$ & $04: 15: 32$ \\
Mode & Interferometric Wide swath (IW) & Interferometric Wide swath (IW) \\
Satellite & Sentinel-1B & Sentinel-1A \\
Absolute orbit number & 24037 & DESCENDING \\
Pass direction & DESCENDING & W + VH \\
Polarization & W + VH & Single Look Complex (SLC) \\
Product type & Single Look Complex (SLC) & 36 \\
Path & 36 & 467
\end{tabular}

Table 3 Sentinel-1 images used for the InSAR analysis (ascending orbit)

\begin{tabular}{|c|c|c|}
\hline Name & $\begin{array}{l}\text { Characteristics } \\
\text { Prior to the event (reference-D1) }\end{array}$ & $\begin{array}{l}\text { Characteristics } \\
\text { After the event (secondary-D2) }\end{array}$ \\
\hline Date & 24th Oct. 2020 & 30th Oct. 2020 \\
\hline Time (UTC) & $16: 06: 24$ & $16: 07: 08$ \\
\hline Mode & Interferometric Wide swath (IW) & Interferometric Wide swath (IW) \\
\hline Satellite & Sentinel-1B & Sentinel-1A \\
\hline Absolute orbit number & 23957 & 35028 \\
\hline Pass direction & ASCENDING & ASCENDING \\
\hline Polarization & $\mathrm{V}+\mathrm{VH}$ & $\mathrm{V}+\mathrm{VH}$ \\
\hline Product type & Single Look Complex (SLC) & Single Look Complex (SLC) \\
\hline Path & 131 & 131 \\
\hline Frame & 118 & 119 \\
\hline
\end{tabular}




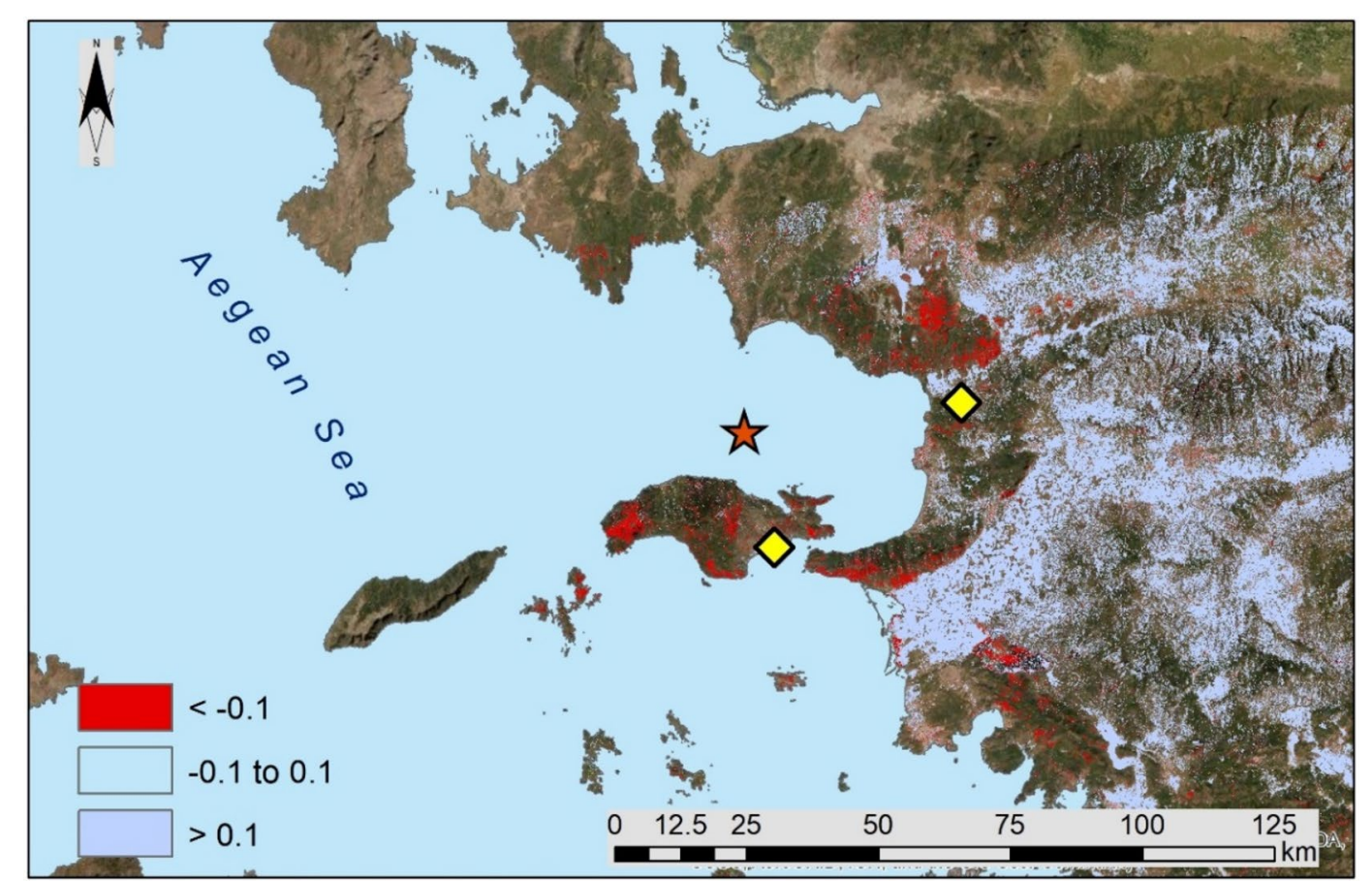

Fig. 2 Change detection maps as derived from the Sentinel-1 SAR images (Table 1) using the VH log difference and VV log difference. Earthquake's epicentre is shown with the red star, while the UNESCO World Heritage properties are shown with a yellow colour ("Pythagoreion and Heraion of Samos" of the left and "Ephesus" on the right)

correlating the damages resulting from the earthquake, it can be used as a damage and change detection proxy map for assisting local authorities [43]. Change detection analysis indicated negative differences in the west of the "Pythagoreion and Heraion of Samos" site and the North of "Ephesus".

A similar pattern as those of the change detection analysis is also observed in the coherence maps (see Fig. 3) for descending (Fig. 3a) and ascending (Fig. 3b) orbits. Low coherence values, close to zero, can be linked with changes over the area. Significant changes are observed in the north-western part of the island of Samos in both change detection analysis and the coherence maps.

The previous result indicates that changes have been observed in the radar signal at both the "Pythagoreion and Heraion of Samos" and in the "Ephesus" archaeological site $(\log 10(\mathrm{D} 2 / \mathrm{D} 1<-0.1)$. These changes should be primarily linked with surface displacements (deformation) of the site ("Pythagoreion and Heraion of Samos") due to the earthquake event. For this reason, an InSAR analysis was followed.

\section{InSAR analysis}

With InSAR analysis, various products can be generated, as these are presented below. These products should be taken into consideration with caution, as in any satellite remote sensing application, as these need to be verified with ground measurements. However, as in our case, these results can be used as a first proxy map of the impact of the earthquake for monitoring purposes of UNESCO World Heritage sites.

The first result generated from the InSAR processing is the wrapped interferogram. Wrapped interferogram indicates phase fringes corresponding to half the radar wavelength [44]. Figure 4 shows the deformation fringes related to the earthquake of 30th Oct. 2020, as derived from the Sentinel-1 SAR images in descending (Fig. 4a) and ascending (Fig. 4b), in $\mathrm{mm}$. Each estimated fringe corresponds to a change in range of $\lambda / 2$, where $\lambda$ is the Sentinel-1 radar wavelength (estimated to $5.54 \mathrm{~cm}$ for the Sentinel-1 radar satellite). The closer the fringes are together, the higher the deformation on the ground. Though that the different viewing geometry of the ascending and descending orbits and the different period of observation, Fig. 4a, b results show some similarities, such as the ground movement of the north-western part of the island of Samos and the western part of Asia Minor just west of the island. The epicentre of the earthquake is shown in Fig. 4 with a red star.

The unwrapped interferogram as derived from the Sentinel-1 SAR images related to the earthquake of 30th Oct. 2020, in descending and ascending orbits, is shown 

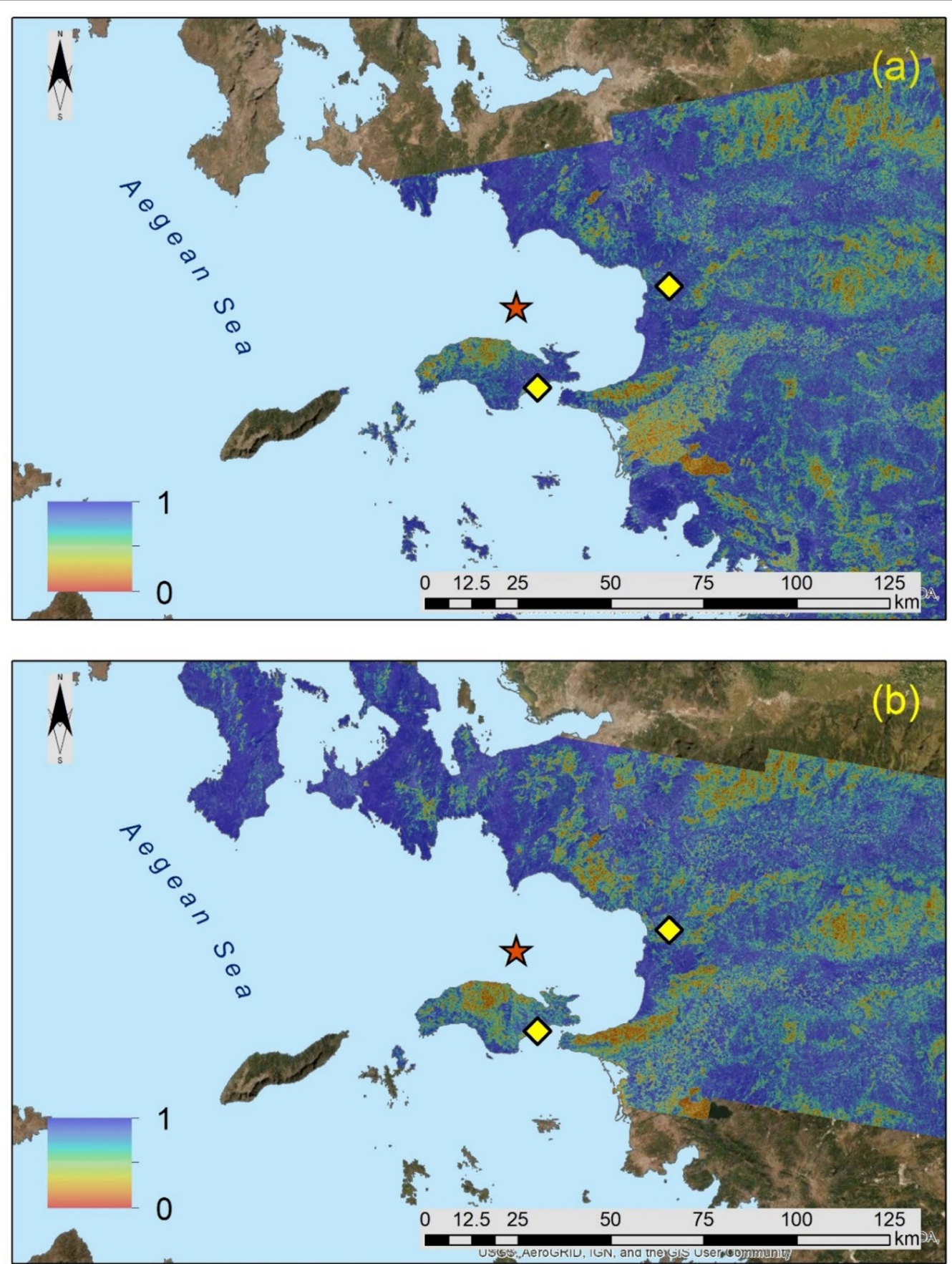

Fig. 3 Coherence maps as derived from the Sentinel-1 SAR images from the descending (Fig. 3a, Table 2) and the ascending (Fig. 3b, Table 3) orbits. Earthquake's epicentre is shown with the red star, while the UNESCO World Heritage properties are shown with a yellow colour ("Pythagoreion and Heraion of Samos" of the left and "Ephesus" on the right)

in Fig. 5. The unwrapped interferogram is a continuous scale (of multiples of pi) of the wrapped 2- $\pi$ scale (Fig. 4). This procedure was executed in the HyP3 cloud platform using the Minimum Cost Flow (MCF).
It should be mentioned that the unwrapped values, as shown in Fig. 5, corresponds to the change in the distance along the line of sight (LOS) of the sensor. Positive values indicate movement away from the sensor 

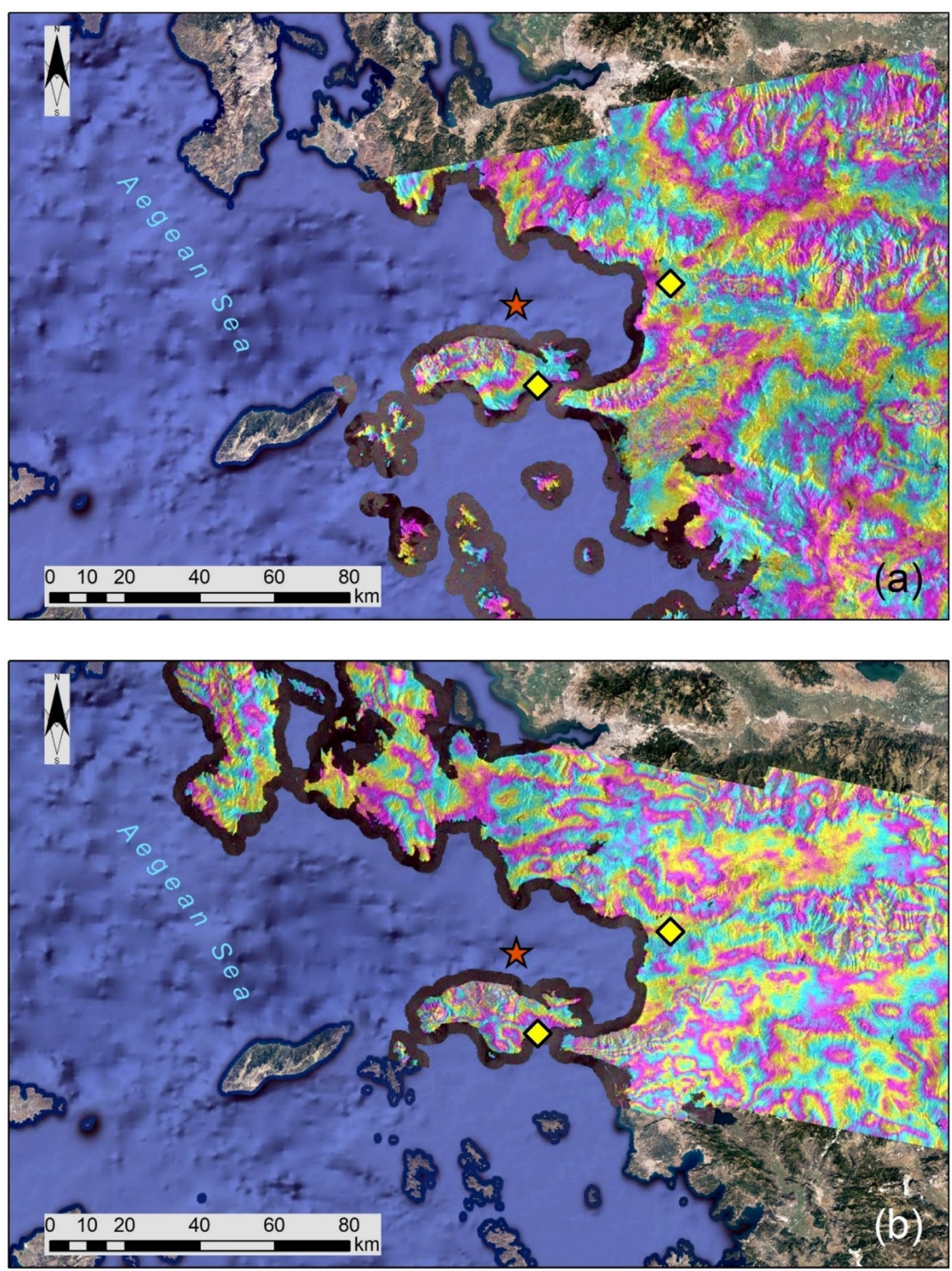

Fig. 4 Deformation fringes related to the earthquake of 30th Oct. 2020, as derived from the Sentinel-1 SAR images in descending (Fig. 4a, Table 2) and ascending (Fig. 4b, Table 3) orbits. Earthquake's epicenter is shown with the red star, while the UNESCO World Heritage properties are shown with a yellow colour ("Pythagoreion and Heraion of Samos" of the left and "Ephesus" on the right) (units:- $\pi$ to $+\pi, 0-28 \mathrm{~mm}$ )

(subsidence), while negative values indicate movement towards the sensor (uplift). The uplift observed on the island of Samos has been interpreted by [45] because of co-seismic motion along a normal offshore fault. This fault runs through the E-W direction and dipping to the North.

The final product of the InSAR analysis is a relative vertical displacement map generated from both ascending 

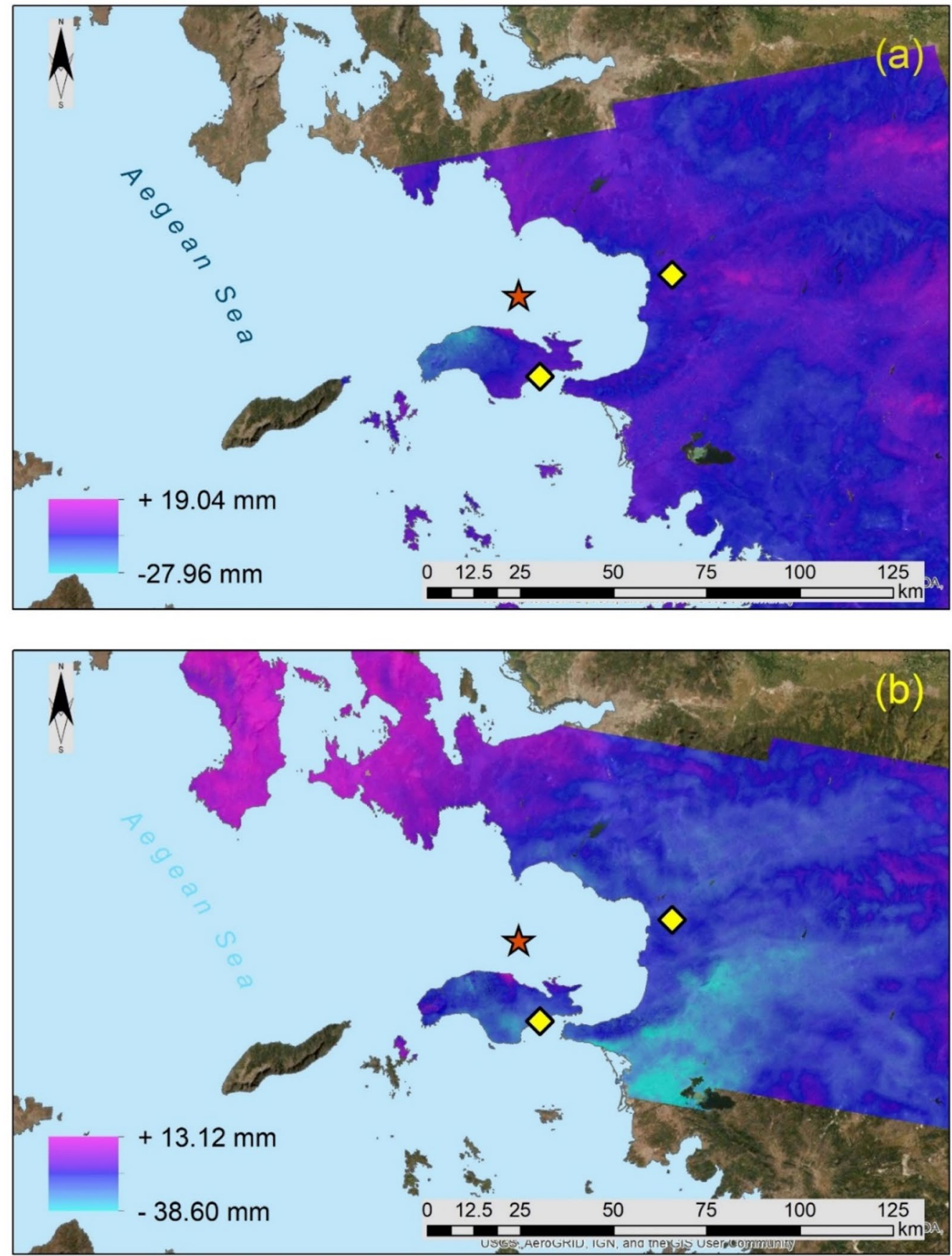

Fig. 5 Unwrapped interferogram as derived from the Sentinel-1 SAR images related to the earthquake of 30th Oct. 2020, in descending (Fig. 5a, Table 2) and ascending (Fig. 5b, Table 3) orbits. Earthquake's epicenter is shown with the red star, while the UNESCO World Heritage properties are shown with a yellow colour ("Pythagoreion and Heraion of Samos" of the left and "Ephesus" on the right)

and descending orbits, through the HyP3 platform. The results of the relative vertical displacement analysis are shown in Fig. 6. Once again, values greater than zero (0) indicate an uplift phenomenon, while value lower than zero (0) indicate subsidence. The north-western part of the island of Samos indicates a relative uplift phenomenon. These estimations of a general uplift of the island by $18-25 \mathrm{~cm}$ were also reported in the media [46]. 


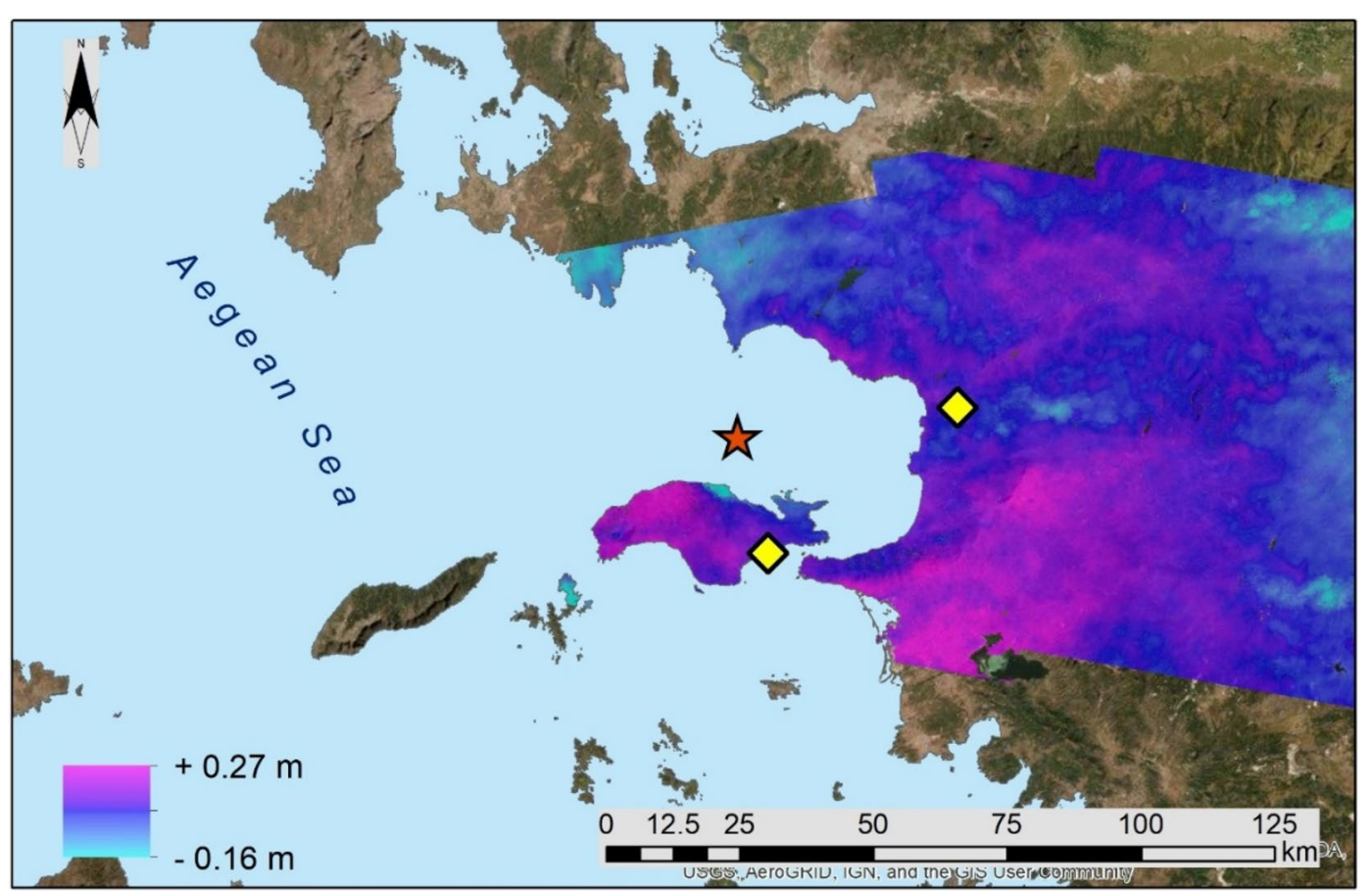

Fig. 6 Relative vertical displacement as derived from the Sentinel-1 SAR images from the descending (Fig. 6a, Table 2) and the ascending (Fig. 6b, Table 3) orbits. The earthquake's epicentre is shown with the red star. In contrast, the UNESCO World Heritage properties are shown with a yellow colour ("Pythagoreion and Heraion of Samos" of the left and "Ephesus" on the right)

The InSAR analysis indicates vertical displacement over the surface near the "Pythagoreion and Heraion of Samos" site, estimated at $+0.08 \mathrm{~m}$ uplift phenomenon. In comparison, for the area of "Ephesus" this was estimated to be at $+0.07 \mathrm{~m}$. While these estimations for the uplift phenomenon are estimated on a relative basis, not absolute measurements through ground stations, the results indicate a similar trend for both case studies after the earthquake event.

\section{Optical processing}

Optical Sentinel-2 image was used in the case of the archaeological site of "Paphos" in Cyprus. The Sentinel-2 multispectral image, with an acquisition date of 05th Oct. 2020 was processed through a supervised classification to map urban areas in the vicinity of the protected site. The classification process was performed through the Sentinel Application Platform (SNAP), using the Random Forest (RF) classifier. Training areas were selected through visual interpretation of the multispectral image, using different pseudo colour composites. The accuracy was estimated to be more than $96 \%$, while the precision was found to be more than $86 \%$ for all thematic classes used in training (i.e. urban, water, vegetation, and soil).

The classification results from the Sentinel-2 image are shown in Fig. 7e, while a closer look around the area of the "Nea Paphos" and the "Tombs of the Kings" (both enlisted under the "Paphos" UNESCO World Heritage property) is shown in Fig. 7f. Urban areas are indicated with a red colour. A visual interpretation of the result can be performed from a high-resolution optical image shown in Fig. 7a, b (images from ESRI ArcGIS). Fig. 7c, $\mathrm{d}$ show the classification result of the same areas as depicted from the CORINE Land Use Land Cover program of the 2000 survey. Once again, the urban areas are depicted with red colour.

Comparing the CORINE 2020 dataset (Fig. 7c, d) with the classification analysis of 2020 (Fig. 7e, f), it is evident that urban areas have been expanded in the southern part of the archaeological site of "Nea Paphos" (black circle on Fig. 7f). Comparable observations can also be reported for the northern and eastern part of the "Tombs of the Kings" archaeological site (black dashed circle at Fig. 7f).

\section{Discussion}

The previous results indicate some of the potential benefits of earth observation sensors to support UNESCO World Heritage properties worldwide. The technological changes observed in the last decade in terms of the provision of higher resolution radar and optical datasets and the big-earth data cloud platform processing can 

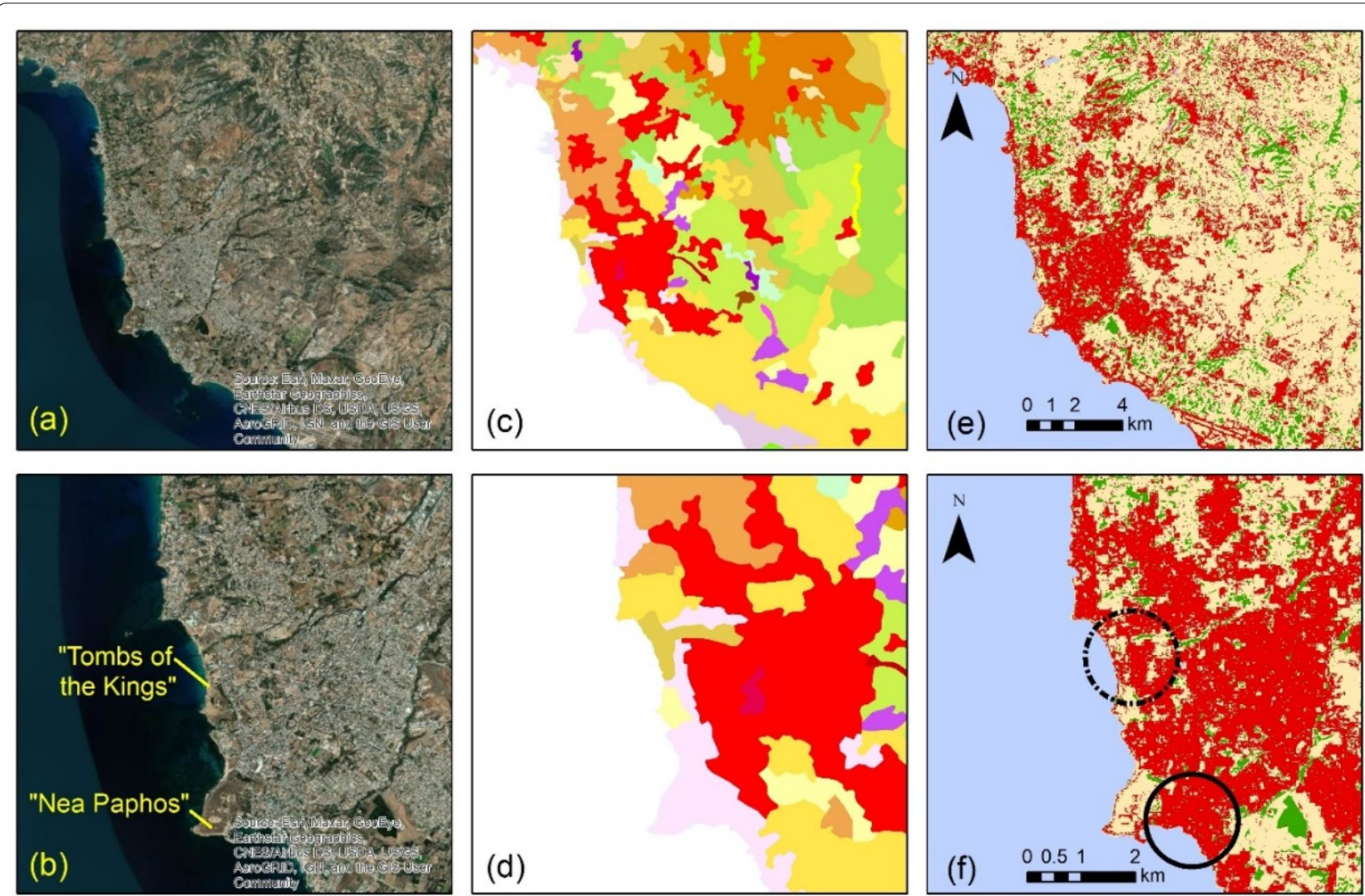

Fig. 7 a High-resolution satellite image over the UNESCO World Heritage site of "Paphos". b a closer look at the archaeological sites of "Nea Paphos" and the "Tombs of the Kings". c CORINE Land Use Land Cover dataset over the area from the 2000 campaign. Urban areas are shown with red colour. d a closer look at the CORINE dataset as before. e Classification results of the Sentinel-2 image taken in 2020. Urban areas are shown with red colour and $\mathbf{f}$ a closer look at the classification results of Fig. 7 e as before

increase the applicability of remotely sensed sensors to this domain.

As presented in the case studies of "Pythagoreion and Heraion of Samos" and "Ephesus", the radar-related products showcases that Copernicus Sentinel-1 images can provide in a few hours proxy maps for large areas in relation to land displacements after an earthquake event. The utilization of satellite-based monitoring assessment has apparent advantages, especially in areas that are limited to access. The use of space-borne sensors can be used to retrieve information on sites, especially in cases where this cannot be performed on the ground. As already mentioned by [47], this kind of analysis can provide details for monitoring sites over an extensive period and provide reliable results regarding the main factors that might endanger the cultural heritage site as a basis for future preservation measures. This information remains important as it can provide in a short period, especially after emergencies like earthquake events

The previous results have showcase the contribution of satellite sensors for detecting changes after specific events, hazards and other emergencies, like the earthquake event near the Samos island. The processing of satellite image in short time, with the use of big-data cloud platforms can provide outcomes to local stakeholders for studying the impact of the event. Furthermore, multitemporal changes that took place through an extensive period, as the example of the urban sprawl of almost 2 decades in the area of Paphos city, can also be studied through optical imageries. Therefore, satellite sensors and image processing can highlight changes and damages, corroborate some hypotheses or unveil otherwise unknown aspects related to the conservation of heritage sites.

The role of earth observation as a monitoring tool for archaeological sites is indicated in Fig. 8 below. White traditional methods for monitoring sites with archaeological interest are mainly focused on periodic observations and in situ campaigns, there might be a gap of observation when an emergency event like a hazard (e.g. earthquakes) is occurred. In contrary earth observation sensors can deliver systematic data, covering large areas 


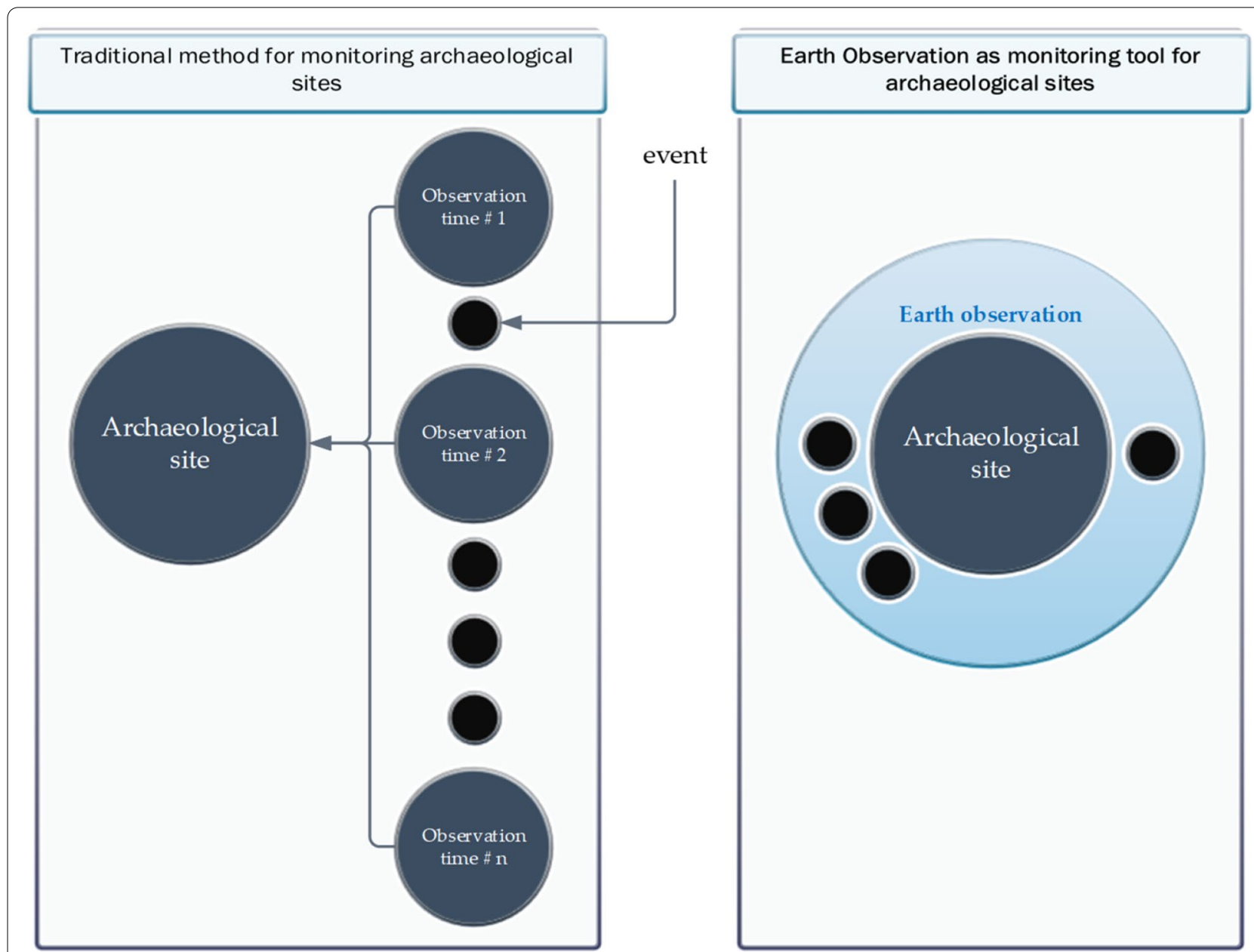

Fig. 8 A schematic approach for indicating traditional methods for monitoring archaeological sites through inside observations in periodic times (left). the role of elephant survey shun as a monitoring tool of archaeological sites (right). Emergency events like hazards (e.g. earthquakes) are shown with black dots

and therefore provide accurate and in short-time information even after the event of an earthquake and other hazards.

However, despite the high accuracy of the vertical displacement maps and the line-of-sight products, these measurements remain relative. Relative ground movements and displacements should be linked with ground data like Global Navigation Satellite Systems (GNSS) for validation purposes. Similar observation can also be reported for the optical processing of the Sentinel-2 image for mapping urban areas. These results need to be validated and confirm with ground investigations. However, the use of satellite-based products and reltive results are fundamental for understanding the context of the archaeological site, especially when this context is changing.

\section{Conclusion}

The geographical distribution of UNESCO World Heritage Sites around the globe highlights the importance of the development of a systematic observation tool, especially for monitoring purposes after a disastrous event, like a natural hazard.

The use of ready products like those of the CORINE datasets, the access to big-data earth observation platforms (like the HyP3), the fully and freely distributed policy of the Copernicus program (freely distributed Sentinel datasets and software platforms like the SNAP) were presented above. In this paper, freely distributed and open-access satellite sensors were used for selected UNESCO World Heritage site in the Eastern Mediterranean basin. Both radar and optical Copernicus Sentinel satellite data were processed and analyzed towards the 
better understanding of anthropogenic and natural hazards in the vicinity these UNESCO World Heritage sites. A recent earthquake event north of the island of Samos, as well as slowly driven changes from the urban expansion, have been presented as case studies.

The article summarized some of the benefits of the use of earth observation, also highlighting the changes that are currently taken place in the domain of the space sector. Indeed, the traditional way of remote sensing is expected to change in the near future. The use of big-data earth observation cloud platforms like HyP3 and the use of open access software like SNAP, showcase the technological shift towards the use of ready products and services. This change can only act for the benefit of the cultural heritage sector: more reliable data will be becoming accessible to end-users and stakeholders responsible for the protection of heritage sites, including UNESCO World Heritage properties.

This type of analysis and the results generated here need to take into consideration other ground (truth) data for validation purposes. Again, this information then should be seen an input layer of the context of a site towards its better protection and preservation.

The effort should be expanded not only to the optimization of the data and services but to how these space-based related technological changes can be fully exploited for the benefit of the cultural heritage sector, like the systematic monitoring of the sites. The challenge to this is expected to be not to the data processing per se, but rather to the development of sophisticated methodologies for the automation of the imaging process to be delivered ready products that can be used by local and national stakeholders.

\section{Acknowledgements}

The author would like to acknowledge the International Centre on Space Technologies for Natural and Cultural Heritage (HIST) for covering the open access publication fees of the paper. The author would like to acknowledge the ASF DAAC 2020 using GAMMA software. The articles contain modified Copernicus Sentinel data 2020, processed by ESA. The author would like also to acknowledge the use of free open-access Copernicus Sentinel-2 data and the use of SNAP_ESA Sentinel Application Platform v8.0.0, http://step.esa.int.

\section{Authors' contributions}

AA: conceptualization, methodology, investigation, writing and visualization. The author read and approved the final manuscript.

\section{Funding}

This paper is submitted under the NAVIGATOR project. The project is being co-funded by the Republic of Cyprus and the Structural Funds of the European Union in Cyprus under the Research and Innovation Foundation grant agreement EXCELLENCE/0918/0052 (Copernicus Earth Observation Big Data for Cultural Heritage).

\section{Availability of data and materials}

CORINE Land Use and Land Cover data can be accessed through the European Environmental Agency (EEA) Corine Land Cover (CLC) (https://land. copernicus.eu/pan-european/corine-land-cover/clc-2000?tab=metadata). Sentinel-1 and Sentinel-2 results can be accessed through the KTISIS open access institutional repository of the Cyprus University of Technology (https:// ktisis.cut.ac.cy/cris/project/pj00350)

\section{Declarations}

\section{Competing interests}

The author declares no conflict of interest.

\section{Author details}

${ }^{1}$ Department of Civil Engineering and Geomatics, Faculty of Engineering and Technology, Cyprus University of Technology, Saripolou 2-8, 3036 Limassol, Cyprus. ${ }^{2}$ Eratosthenes Centre of Excellence, Saripolou 2-8, 3036 Limassol, Cyprus.

Received: 20 March 2021 Accepted: 21 May 2021

Published online: 01 June 2021

\section{References}

1. World Heritage List. (2020) https://whc.unesco.org/en/list/?\&type= mixed. Accessed 30th Nov 2020

2. World Heritage List Statistics. (2020) https://whc.unesco.org/en/list/stat\# d1. Accessed 30th Nov 2020

3. UNESCO (Paris). Managing Disaster Risks for World Heritage; World Heritage Resource Manual; United Nations Educational, Scientific and Cultural Organization (UNESCO): Paris, France; 2010. p. 69

4. Nicu IC. Natural risk assessment and mitigation of cultural heritage sites in North-eastern Romania (Valea Oii river basin). Area. 2019;51:142-54. https://doi.org/10.1111/area.12433.

5. Lombardo L, Tanyas H, Nicu IC. Spatial modeling of multi-hazard threat to cultural heritage sites. Eng Geol. 2020;277:105776. https://doi.org/10. 1016/j.enggeo.2020.105776.

6. Maio R, Miguel Ferreira T, Vicente R. A critical discussion on the earthquake risk mitigation of urban cultural heritage assets. Int J Disaster Risk Reduct. 2018;27:239-47. https://doi.org/10.1016/j.jjdrr.2017.10.010.

7. Dawson RA, Petropoulos GP, Toulios L, Srivastava PK. Mapping and monitoring of the land use/cover changes in the wider area of Itanos, Crete, using very high resolution EO imagery with specific interest in archaeological sites. Environ Dev Sustain. 2020;22:3433-60.

8. Agapiou A, Alexakis DD, Lysandrou V, Sarris A, Cuca B, Themistocleous K, Hadjimitsis DG. Impact of Urban Sprawl to archaeological research: the case study of Paphos area in Cyprus. J Cult Herit. 2015;16:671-80.

9. Nicu IC. Cristian Constantin Stoleriu, land use changes and dynamics over the last century around churches of Moldavia, Bukovina, Northern Romania_challenges and future perspectives. Habitat Int. 2019;88:101979. https://doi.org/10.1016/j.habitatint.2019.04.006.

10. Agapiou A, Lysandrou V, Hadjimitsis DG. Earth observation contribution to cultural heritage disaster risk management: case study of Eastern Mediterranean open air archaeological monuments and sites. Remote Sens. 2020;2:1330.

11. Fattore C, Abate N, Faridani F, Masini N, Lasaponara R. Google earth engine as multi-sensor open-source tool for supporting the preservation of archaeological areas: the case study of flood and fire mapping in Metaponto Italy. Sensors. 2021;21:1791. https://doi.org/10.3390/s21051791.

12. Lysandrou V, Agapiou A. The role of aerial photography in shaping our understanding of the funerary landscape of Hellenistic and Roman Cyprus. Open Archaeol. 2020;6:417-33.

13. Cowley D, Ferguson L. Historic aerial photographs for archaeology and heritage management. In: Forte M, Campana S, Liuzza C, editors. Space, time, place. Third international conference on remote sensing in archaeology, BAR, International Series 2118. Oxford: Archaeopress; 2018. p. 97-104.

14. Cowley DC, Stichelbaut B. Historic aerial photographic archives for European Archaeology. Eur J Archaeol. 2012;15(2):217-36. https://doi.org/10. 1179/1461957112Y.0000000010.

15. Opitz R, Herrmann J. Recent trends and long-standing problems in archaeological remote sensing. J Comput Appl Archaeol. 2018;1:19-41. 
16. Alexakis D, Sarris A, Astaras T, Albanakis K. Detection of neolithic settlements in thessaly (Greece) through multispectral and hyperspectral satellite imagery. Sensors. 2009;9:1167-87.

17. Gallo D, Ciminale M, Becker H, Masini N. Remote sensing techniques for reconstructing a vast Neolithic settlement in Southern Italy. J Archaeol Sci. 2009;36:43-50.

18. Lasaponara R, Masini N. Beyond modern landscape features: new insights in the archaeological area of Tiwanaku in Bolivia from satellite data. Int J Appl Earth Obs Geoinform. 2014;26:464-71.

19. Luo L, Wang X, Guo H, Lasaponara R, Zong X, Masini N, Wang G, Shi P, Khatteli $\mathrm{H}$, Chen $\mathrm{F}$, et al. Airborne and space-borne remote sensing for archaeological and cultural heritage applications: a review of the century (1907-2017). Remote Sens Environ. 2019;232:111280.

20. Agapiou A, Lysandrou V. Remote sensing archaeology: tracking and mapping evolution in scientific literature from 1999-2015. J Archaeol Sci Rep. 2015:4:192-200.

21. Tapete D, Cigna F. Poorly known 2018 floods in Bosra UNESCO site and Sergiopolis in Syria unveiled from space using Sentinel-1/2 and COSMO-SkyMed. Sci Rep. 2020;10:12307. https://doi.org/10.1038/ s41598-020-69181-x.

22. Tapete D, Cigna F. COSMO-SkyMed SAR for detection and monitoring of archaeological and cultural heritage sites. Remote Sens. 2019;11:326.

23. Agapiou A. Detecting looting activity through earth observation multitemporal analysis over the archaeological site of Apamea (Syria) during 2011-2012. JCAA. 2020;3(1):219-37. https://doi.org/10.5334/jcaa.56.

24. Casana J. Satellite imagery-based analysis of archaeological looting in Syria. Near East Archaeol. 2015;78:142-52. https://doi.org/10.5615/neare astarch.78.3.0142.

25. Orengo $\mathrm{H}$, Petrie $\mathrm{C}$. Large-scale, multi-temporal remote sensing of palaeo-river networks: a case study from Northwest India and its implications for the Indus civilisation. Remote Sens. 2017;9:735.

26. Agapiou A. Remote sensing heritage in a petabyte-scale: satellite data and heritage Earth Engine@ applications. Int J Digit Earth. 2017;10(1):85102. https://doi.org/10.1080/17538947.2016.1250829.

27. Orengo HA, Conesa FC, Garcia-Molsosa A, Lobo A, Green AS, Madella M, Petrie CA. Automated detection of archaeological mounds using machine-learning classification of multisensor and multitemporal satellite data. Proc Natl Acad Sci USA. 2020;117(31):18240-50. https://doi.org/ 10.1073/pnas.2005583117.

28. Agapiou A, Lysandrou V. Detecting displacements within archaeological sites in Cyprus after a 5.6 magnitude scale earthquake event through the hybrid pluggable processing pipeline (HyP3) cloud-based system and sentinel-1 interferometric synthetic aperture radar (InSAR) analysis. IEEE J Sel Top Appl Earth Obs Remote Sens. 2020;13:6115-23. https://doi.org/ 10.1109/JSTARS.2020.3028272.

29. Agapiou A, Alexakis DD, Hadjimitsis DG. Potential of virtual earth observation constellations in archaeological research. Sensors. 2019;19:4066.

30. Paphos Theatre Archaeological Project. (2021) http://www.paphosthea tre.org. Accessed 19th May. 2021
31. Ephesus. (2020) https://whc.unesco.org/en/list/1018. Accessed 30th Nov. 2020

32. Pythagoreion and Heraion of Samos. (2020) https://whc.unesco.org/en/ list/595. Accessed 30th Nov. 2020

33. Copernicus. (2020) https://www.copernicus.eu/en. Accessed 30th Nov. 2020

34. Sentinel 1, Geographical Coverage. (2020) https://sentinel.esa.int/web/ sentinel/missions/sentinel-1/satellite-description/geographical-cover age. Accessed 30th Nov 2020

35. Sentinel-2. (2020) https://sentinel.esa.int/web/sentinel/missions/senti nel-2. Accessed 30th Nov 2020

36. Alaska Satellite Facility (ASF). (2020) https://asf.alaska.edu. Accessed 30th Nov 2020

37. Sentinel Data Hub. (2020) https://scihub.copernicus.eu. Accessed 30th Nov 2020

38. About HyP3. (2020) https://hyp3.asf.alaska.edu/about. Accessed 30th Nov 2020

39. Werner $\mathrm{CL}$, Wegmüller U, Strozzi T. Processing strategies for phase unwrapping for InSar applications (2002) https://www.gamma-rs.ch/ uploads/media/2002-4_PhaseUnwrapping.pdf. Accessed 30th Nov 2020

40. Breiman L. Random Forests. Mach Learn. 2001;45:5-32.

41. Sentinel Application Platform (SNAP). (2020) https://step.esa.int/main/ toolboxes/snap. Accessed 30th Nov 2020

42. Corine Land Cover (CLC). (2000) https://land.copernicus.eu/pan-europ ean/corine-land-cover/clc-2000?tab=metadata. Accessed 30th Nov 2020

43. Agapiou A. Damage proxy map of the beirut explosion on 04th Aug. 2020 as observed from the copernicus sensors. Sensors. 2020;20:6382.

44. Gudmundsson S, Carstensen JM, Sigmundsson F. Unwrapping ground displacement signals in satellite radar interferograms with aid of GPS data and MRF regularization. IEEE Trans Geosci Remote Sens. 2002:40(8):1743-54.

45. Ganas A, Elias P, Briole P, Tsironi V, Valkaniotis S, Escartin J, Karasante I, Efstathiou E. Fault responsible for Samos earthquake identified. Temblor. 2020. https://doi.org/10.32858/temblor.134.

46. TANEA. (2020) https://www.tanea.gr/2020/11/03/greece/seismos-stisamo-kata-18-25-ekatosta-anypsothike-to-nisi-eikones/ Accessed 30th Nov 2020

47. Moise C, Dana Negula I, Mihalache CE, Lazar AM, Dedulescu AL, Rustoiu GT, Inel IC, Badea A. Remote sensing for cultural heritage assessment and monitoring: the case study of Alba lulia. Sustainability. 2021;13:1406. https://doi.org/10.3390/su13031406.

\section{Publisher's Note}

Springer Nature remains neutral with regard to jurisdictional claims in published maps and institutional affiliations.

\section{Submit your manuscript to a SpringerOpen ${ }^{\odot}$ journal and benefit from:}

- Convenient online submission

- Rigorous peer review

- Open access: articles freely available online

- High visibility within the field

- Retaining the copyright to your article

Submit your next manuscript at $\boldsymbol{\Delta}$ springeropen.com 